\title{
Research on Problems of Development of Science under Conditions of Adapting to the Digitalization of the Economy
}

\author{
Mykola Kyzym, Viktoriia Khaustova, Olena Reshetnyak, Natalia Danko
}

\begin{abstract}
The digital economy can lead to an increase in the inequality between advanced countries and developing ones, which cannot keep pace with changes in the modern world. Nations that want to be competitive in the future need to develop digital technologies using their own scientific potential. The complexity, multidimensionality, and ill-structuredeness of problems related to adaptation of countries to the digitalization of the economy require using the cognitive approach. The aim of the article is to study the development of science under conditions of countries' adapting to the digitalization of the economy with the use of the cognitive approach. A methodological approach to studying problems of development of science under conditions of adapting to the digitalization of the economy is proposed. In accordance with the methodological approach, a cognitive model for studying problems of development of science under conditions of a country's adapting to the digitalization of the economy is built. The presented model for studying problems of development of science in Ukraine under conditions of adapting to the digitalization of the economy reveals risks and helps identify opportunities for reforming the scientific sphere.
\end{abstract}

Keywords: digital economy, development of science, adaptation to conditions of the digital economy, science reform, cognitive model

\section{INTRODUCTION}

Trends in the scientific and technological development associated with the spread of digital technologies are considered by many scientists as a key factor in the advancement of countries of the world that helps to ensure their ability to respond to modern challenges and global problems. Digital technologies are rapidly transforming society, making a significant contribution to achieving sustainable development goals, creating new opportunities for the emergence of innovative technologies and products, changing existing technologies and products, forming new and modernizing traditional knowledge. The digitalization of the economy is one of the priority areas of strategic development for most countries-economic leaders, including the USA, Germany, Great Britain, Japan [1].

Revised Version Manuscript Received on 30 May, 2019.

Mykola Kyzym, Director, Research Centre for Industrial Problems of Development of the Nattional Academy of Sciences of Ukraine, Kharkiv, Ukraine. (Email: ndc_ipr@ukr.net)

Viktoriia Khaustova, Section for Industrial Policy and Innovative Development, Research Centre for Industrial Problems of Development of the National Academy of Sciences of Ukraine, Kharkiv, Ukraine. (Email: v.khaust@gmail.com)

Elena Reshetnyak, Department of International E-Commerce and Hotel and Restaurant Business of V. N. Karazin Kharkiv National University, Kharkiv, Ukraine. (Email: olena.reshetnyak@karazin.ua)

Natalia Danko, Department of International E-Commerce and Hotel and Restaurant Business of V. N. Karazin Kharkiv National University, Kharkiv, Ukraine. (Email: n.danko@karazin.ua)
The digital economy in the modern world is considered to be the main source of growth in labor productivity, competitiveness, volume of investment and innovation. It leads to improved quality of services; creates new jobs [2]; ensures reduction in production costs [3]. The digital economy is a new economy that is based on knowledge and digital technologies, within the framework of which new digital skills and opportunities are being formed in the life of society, business and the state [3]. The essence of the digital economy is considered with regard to several scopes of relevance, namely, Core: Digital (IT/ICT) Sector (Hardware manufacture, Software \& IT consulting, Information services, Telecommunications); Narrow Scope: Digital Economy (Digital services, Platform economy); Broad Scope: Digitalized Economy (Sharing economy, Gig economy, e-Business, e-Commerce, Industry 4.0, Precision agriculture) [4].

The widespread application of digital technologies is radically changing life sciences. It brings about the emergence of new areas of research (bioinformatics, geoinformatics, cell technologies, genomics, synthetic biology, neurotechnology, artificial intelligence, machine learning, etc.); modernization of modern medicine, engineering, agriculture and other traditional sectors of the economy. The digitalization of industrial production includes virtual modeling, the Internet of things, robotics, artificial intelligence, cloud and edge computing technologies, predictive analytics, etc. As a result of digitalization, training methods and technologies (online technologies) are changing; new financial instruments (cryptocurrency), accounting technologies (blockchain) are emerging; obsolete professions are disappearing, and fundamentally new ones are being created; new customer centric business models, the key source of which is high-speed big data processing, are being developed.

Under the influence of digital technologies, radical changes are taking place in the organization and methods of scientific research, forms of employment in science, methods for collecting and analyzing information, and mechanisms for commercializing the results of intellectual activity. The digitalization makes science more open [5], encourages researchers to work together through new digital platforms for scientific research. 
However, it is necessary to understand that the digital economy can lead to an increase in the inequality between advanced countries and developing ones, which cannot keep pace with changes in the modern world. Nations that want to be competitive in the future need to develop digital technologies using their own scientific potential. Therefore, considering problems of development of science in countries of the world under conditions of adapting to the digitalization of the economy is relevant today.

\section{LITERATURE REVIEW}

The development of the digital economy and problems of a growing digital inequality are in the focus of attention of many researchers all over the world, including: R. Bukht, R. Heeks [6], T. Elmasry [7]. However, the complexity, multidimensionality, and ill-structuredeness of problems associated with countries' adapting to the digitalization of the economy require applying the cognitive approach, which allows investigating complex ill-structured problems.

The application of the cognitive approach to investigating complex socio-economic problems is considered in works of
Z. Avdeeva, S. Kovriga [8], L. Ginis, G. Gorelova, A. Kolodenkova [9], M. Kyzym [10], and others. However, studying problems of development of science under conditions of countries' adapting to the digitalization of the economy with the use of the cognitive approach has not been conducted yet.

Thus, the aim of the article is studying problems of development of science under conditions of countries' adapting to the digitalization of the economy with the use of the cognitive approach.

\section{RESEARCH METHODOLOGY}

The analysis of the existing theory and practice of investigating complex ill-structured problems with the use of cognitive modeling [8] - [10] made it possible to formulate a methodological approach to studying problems of development of science under conditions of countries' adapting to the digitalization of the economy, which is shown in Fig. 1.

\begin{tabular}{|c|c|c|}
\hline \multicolumn{2}{|c|}{ 1. Studying the research object } & Verbal model of the problemsituation \\
\hline \multirow{3}{*}{$\begin{array}{l}\text { 1.1. Describing a } \\
\text { problemsituation }\end{array}$} & 1.1.1. Firing the ritasuion & Factors confirmine the svmotoms \\
\hline & 1.1.2. Deliminen deacigeten of the goblem & Description of the initial situation \\
\hline & 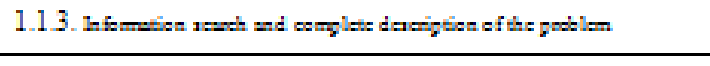 & Hypo thesis of influence on the problensituation \\
\hline \multirow{3}{*}{$\begin{array}{l}\text { 12. Compiling a } \\
\text { catalog of } \\
\text { problems }\end{array}$} & 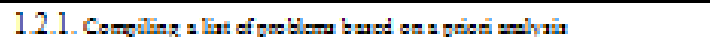 & \multirow{2}{*}{ Cataloz of wroblems $\mathrm{Si}(\mathrm{i}=0)$} \\
\hline & 1.2.2. Supplementing the cealag of youblem & \\
\hline & 1.23. Reduch g te cealag of goublem & Blocks of problems $\mathrm{Bj} S \mathrm{Si}(\mathrm{j}=0 ; \mathrm{i}=0)$ \\
\hline \multicolumn{3}{|r|}{ (1) } \\
\hline \multirow{4}{*}{$\begin{array}{l}\text { 13. Forming } \\
\text { (gouping) blocks } \\
\text { of problems }\end{array}$} & 1.3.1. Azzenzetion of the robilen & \multirow{3}{*}{$\begin{array}{l}\text { Determining the weight of the problems based } \\
\text { on the AnalyticHierachy Process developed by } \\
\text { T. Saaty (Matrix L) }\end{array}$} \\
\hline & 132. Breking the rosblems out ins blocka & \\
\hline & 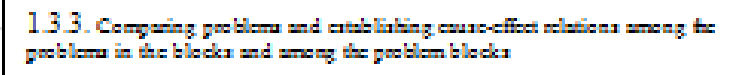 & \\
\hline & 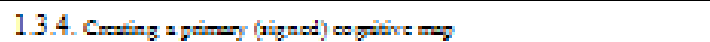 & Primary cognitive map \\
\hline \multirow{5}{*}{$\begin{array}{l}\text { 1.4. Detenrining } \\
\text { the degres of } \\
\text { importance of the } \\
\text { problems. } \\
\text { presenting the } \\
\text { blocks of problems } \\
\text { and slations anong } \\
\text { them }\end{array}$} & 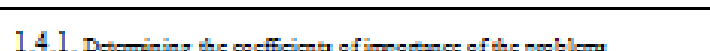 & \multirow[t]{2}{*}{ Types of problens: root, nodal, resulting } \\
\hline & & \\
\hline & 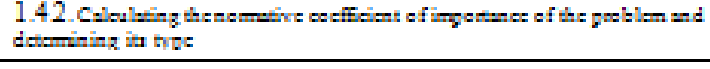 & $\begin{array}{l}\text { Calculation of corelation cofficients } \\
\text { Matrix A }\end{array}$ \\
\hline & 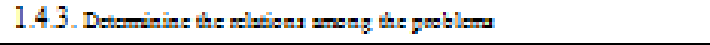 & Vector of intial vahes $\mathrm{X}^{\mathrm{x}} \mathrm{Y}(\mathrm{)})$ \\
\hline & 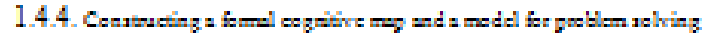 & \multirow{2}{*}{ Formal comitive man $\mathrm{G}=(\mathrm{X} . \mathrm{A} . \mathrm{L})$} \\
\hline & 7 & \\
\hline \multicolumn{2}{|c|}{ 2. Developing recommendations for solving the problen situation } & $\begin{array}{l}\text { Recommendations on directions for solving the } \\
\text { problems ituation and achieving the goals }\end{array}$ \\
\hline
\end{tabular}

Fig. 1. The block diagram of the methodological approach to studying problems of development of science under conditions of adapting to the digitalization of the economy

Let us consider the proposed methodological approach in more detail.

Stage 1. Studying the research object.

\subsection{Describing a problem situation.}

When describing problem situations, it is necessary to identify the fullest extent of knowledge about the priorities and objectives of the functioning of the system, as well as possible means to achieve them. The process of describing a problem situation consists of: fixing the situation (an unordered situation) by forming a visual model; preliminary description of the problem (compilation of available information, identification of missing elements) by forming a verbal model; information search and complete description of 
the problem situation (obtaining additional necessary information and its streamlining).

\subsection{Compiling a catalogue of problems.}

The formed image of the problem situation, as well as a set of statistical indicators which confirm them, make it possible to compile a list of problems which need to be solved to achieve the goal of developing an economic system.

Supplementing the catalog of problems is carried out on the basis of a priori and expert analysis. At this step, the reformulation of problems is also carried out, if necessary, as well as reducing the catalog. Thus, after the formation of a complete list of problems, it is necessary to delete from it those that appear to be insignificant or repeat in another formulation. The source information is the created problem catalog $S_{i}(i=0)$.

\subsection{Forming (grouping) blocks of problems.}

Forming blocks of problems involves the following procedures: aggregating problems (combining problems when necessary, highlighting the most important of them, removing minor problems); breaking the problems out into blocks (in order to simplify the determination of interrelations among the problems and to provide their visibility, problems are grouped into problem blocks according to the criterion of similarity in achieving the goal, which allows to obtain problem blocks $B_{j} S_{i}(j=0 ; i=0)$ ); comparing problems and establishing cause-effect relations among the problems in the blocks and among the problem blocks based on the assumptions of experts.

The next step of this stage is creating a primary (sign) cognitive map which is based on the structuring of knowledge about the problem situation and will be the basis for the further construction of a functional map.

Identification and analysis of problem situations based on a primary cognitive map is one of the key elements in the formation of directions for the desired development of an economic system. Among the variety of formal cognitive maps [8], [10] used to solve various problems related to applying analysis and simulation in managing development of economic systems, functional cognitive maps are most generally employed. Their main element, unlike other cognitive maps, is a functional unit including the behavior of a dependent factor in a node, which is represented by a function (an example of a node is shown in Fig. 2) [8].

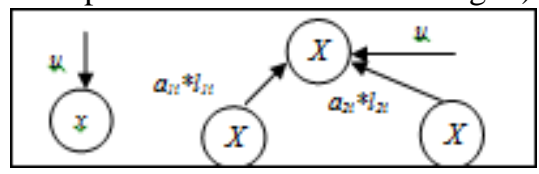

a)

b)

Fig. 2. Acceptable types of factors in a $K_{F}$ - type cognitive map

Let us consider a functional cognitive map of the linear type, which is the basis of the proposed approach to the construction of a model to justify the goals and problems. For a map of the $K_{f 1}$-type, the following types of factors are acceptable: conditionally independent, which are not influenced by other factors of the map and can be changed only through external influences (Fig. 2 (a)), and mixed ones, which may be due to changes in factors of prerequisites and external influence $U$ (Fig. 2 (b)). Let the map $K_{F}$ be defined by the set of factors $X=\left\{x_{1}, \ldots, x_{n}\right\}$ and the set $X_{i}$ of direct causal effects of factors on each other. A direct causal effect can be specified various parameters - variable or constant ones, which may have different interpretations. In this map, factors are assigned the weight of influence (positive or negative), in particular, the weight of the influence of the factor $i$ on the factor $j-a_{i j}$, which can be calculated as the correlation coefficient between the parameters (if the parameters are quantified), or, based on a linguistic evaluation scale, assessments of the interrelations as "strong", "weak" [8], if the parameters cannot be quantified.

Estimates of the mutual interaction of causal factors $a_{i j}$ should be presented as the matrix $A$ of the $n \times n$ size. The parameter $l_{j i}$ is an indicator characterizing the coefficient of importance of the $j^{\text {th }}$ factor according to its influence on the $i^{\text {th }}$ factor. Estimates of the significance of the factors should be presented as the matrix $L$ of the $\mathrm{n} \times \mathrm{n}$ size.

The factor $X$ is prescribed the variables $X(t)$, specified on the basis of a statistical analysis of parameters describing the problem in terms of growth (determined based on statistical data or by the expert method). In the described model, time is conditional and has no predicate interpretation. It is allowed that factors of the map be subject to external influences $U$ (not caused by direct effects from relevant factors) specified in the scale $[-1 ; 1]$ with the corresponding linguistic value of the impact nature.

1.4. Determining the degree of importance of the problems, presenting the blocks of problems and relations among them.

Determining the degree of importance of the problems implies assessing the coefficients of importance by the expert method to solve problems of the same level based on the Analytic Hierarchy Process (AHP) developed by T. Saaty [11].Thus, in this case, using this approach, an indicator characterizing the coefficient of importance of the $j^{\text {th }}$ factor in terms of its influence on the $i^{\text {th }}$ factor $-l_{j i}$ is determined. For this purpose, there carried out comparison of problems within each block and then comparison of the main (root) problems of individual blocks among themselves. In the course of the process, matrices of pairwise comparisons are filled in, the effect of root and nodal problems on other problems is assessed using the scale: 1 - equivalence; 3 - moderate advantage; 5 - strong advantage; 7 - very strong advantage; 9 - superior advantage [11].

The next step is to calculate the normative coefficient of importance of the problem and determine its type.

Based on the experts' assessment of the level of significance of the problems, the normative coefficient of importance of the problem is calculated. The calculation of the normative coefficient of importance is as follows: the elements of each row are summed up and normalized by dividing each amount by the sum of all elements; the sum of the results will be equal to one. The first element of the resulting vector will be the priority of the first object, the second - that of the second object, etc. 
Based on the calculation of the coefficients of importance of a problem in a block of problems, its type is determined root, nodal, resulting or autonomous. Root problems cause or exacerbate other problems; nodal ones are those dependent on certain problems but at the same time cause or exacerbate other problems; resulting ones - those which are the result of other problems; autonomous ones - have a very significant impact but are in no way connected with others. The definition of the type of problems is as follows:

$$
\text { Typeof the problem }\left\{\begin{array}{l}
l_{j i}=0-\text { resulting problem } \\
l_{j i}=(0, \ldots \max )-\text { nodal problem } \\
l_{j i}=\max -\text { root problem }
\end{array}\right.
$$

When building a cognitive map, a necessary step is determining the level of relations among the problems. As defined earlier, to determine the degree of the causal effect of problems and factors that characterize them, the formation of matrices of static data describing their dynamics is carried out. The weight of the influence of the factor $i$ on the factor $j$ is determined by the parameter $a_{i j}$ which is calculated as the coefficient of correlation of quantitative parameters.

It should be noted that for some problems of science development it is impossible to carry out a quantitative analysis of the causal effect of one factor on another. Therefore, the impact is assessed with the use of a linguistic scale for evaluating such relations as "high impact" - value of the causal effect coefficient - 0.942; "considerable impact" 0.618 ; "low impact" -0.309 ; "very low impact" -0.119 by means of the expert analysis. The values of the coefficient of causal effect, proposed in accordance with the approach which takes into account the "golden proportion".

The final step of the second stage of the methodical approach implying the justification of the directions for reforming the scientific sphere in Ukraine in the context of globalization is constructing a formal cognitive map.

The theoretical basis for analyzing the behavior of a complex socio-economic system using the cognitive approach involves constructing a structural chart of the cause-effect relations among the system elements. A model developed on its basis generally includes the following tuple of parameters:

$$
M_{S}=<K_{F}\left(X=\left(X_{\text {int }} \cup X_{\text {int }}\right), A, L, f_{K_{F}}\right) ; C\left(X^{C}, R\left(X^{c}\right)\right) ; X(0) ; U>\quad,
$$

where $K_{F}$ is the cognitive map characterizing the development of an economic system; $A$ - the matrix presenting the values of coefficients of cause-effect relations between the factor $j$ and the factor $i ; L-$ the matrix presenting the values of coefficients of the problem importance; $C$ - the goal image; $X(0)$ - the vector of initial values (estimated by the growth rate of a corresponding indicator); $X_{\text {int }}$ - the indices of internal and external factors characterizing the problem; $U$ - the control vector.

\section{Developing recommendations for solving the problem} situation.

At this stage, based on the obtained results of the system development scenarios, recommendations regarding possible management actions are developed, which makes it possible to increase soundness of making managerial decisions and their effectiveness.

\section{RESULT AND DISCUSSION}

In accordance with the proposed methodological approach (Fig. 1), a cognitive model for studying problems of development of science in Ukraine is built with the aim of adapting the country to conditions of the digital economy. This allowed to formulate the field of existing problems in this area, analyze them taking into account the world experience in using digital technologies, identify the most significant ones, select the main indicators for their assessment, and build a primary cognitive map. The further analysis is aimed at assessing the importance of problems and their interaction using pairwise comparisons based on the Analytic Hierarchy Process developed by T. Saaty [10]. This made it possible to calculate the weighting coefficients for each problem in the group and determine the types of problems based on formula (2) (Table I).

Table- I: Groups representing the main problems of development of science under conditions of adapting to the

\begin{tabular}{|c|c|c|c|c|c|}
\hline Denotation & Problem & Indicator for assessing the problem & Assessment & $\begin{array}{l}\text { Weighting coefficient } \\
\text { of the problem in the } \\
\text { group of problems }\end{array}$ & $\begin{array}{l}\text { Type of } \\
\text { problem }\end{array}$ \\
\hline$X_{1}$ & $\begin{array}{l}\text { Low demand for science in the } \\
\text { economy }\end{array}$ & $\begin{array}{l}\text { Decrease in the share of innovatively } \\
\text { active enterprises (those introducing } \\
\text { information and digital innovations) }\end{array}$ & $\begin{array}{l}\text { Statistical assessment, calculating the } \\
\text { growth rate }\end{array}$ & 0.509 & $\begin{array}{c}\text { nodal } \\
\text { problem }\end{array}$ \\
\hline$X_{2}$ & $\begin{array}{l}\text { Inefficient system of state } \\
\text { management of science }\end{array}$ & $\begin{array}{l}\text { Lack of a strategy for the } \\
\text { development of science in the } \\
\text { country }\end{array}$ & $\begin{array}{l}\text { Expert assessment, linguistic rating, } \\
\text { determining uncertain tendencies }\end{array}$ & 3.922 & $\begin{array}{c}\text { root } \\
\text { problem }\end{array}$ \\
\hline$X_{4}$ & $\begin{array}{l}\text { Lack of funding and other } \\
\text { socio-economic incentives }\end{array}$ & $\mathrm{R} \& \mathrm{D}$ funding & $\begin{array}{l}\text { Statistical assessment, calculating the } \\
\text { growth rate }\end{array}$ & 0.456 & $\begin{array}{c}\text { nodal } \\
\text { problem }\end{array}$ \\
\hline$X_{5}$ & $\begin{array}{l}\text { Low level of effectiveness of } \\
\text { scientific results, low export } \\
\text { potential }\end{array}$ & $\begin{array}{l}\text { Share of exports of high-tech } \\
\text { products }\end{array}$ & $\begin{array}{l}\text { Statistical assessment, calculating the } \\
\text { growth rate }\end{array}$ & 0 & $\begin{array}{l}\text { resulting } \\
\text { problem }\end{array}$ \\
\hline$X_{6}$ & Staffing problem & $\begin{array}{l}\text { Decrease in the number of } \\
\text { researchers }\end{array}$ & $\begin{array}{l}\text { Statistical assessment, calculating the } \\
\text { growth rate }\end{array}$ & 0.502 & $\begin{array}{c}\text { nodal } \\
\text { problem }\end{array}$ \\
\hline$X_{7}$ & $\begin{array}{l}\text { Low level of authority of science } \\
\text { in the society }\end{array}$ & Level of social status of scientists & $\begin{array}{l}\text { Expert assessment, linguistic rating, } \\
\text { determining uncertain tendencies }\end{array}$ & 0.041 & $\begin{array}{c}\text { nodal } \\
\text { problem }\end{array}$ \\
\hline
\end{tabular}
digitalization of the economy and their types in the primary cognitive model 
By analyzing the interrelations among the problems in the primary cognitive map, the values of the matrix $L$ are determined (formula 1 ). The matrix $L$ characterizes the importance of each problem that affects other ones. This influence is evaluated using the Analytic Hierarchy Process developed by T. Saaty [11]. The results are shown in Table II.

The next stage in assessing problems of development of

Table- II: Matrix L, presenting the values of importance coefficients of the problems considered in the cognitive

model

\begin{tabular}{|c|l|c|c|c|c|c|c|c|}
\hline Denotation & \multicolumn{1}{|c|}{ Group of problems } & $X_{1}$ & $X_{2}$ & $X_{3}$ & $X_{4}$ & $X_{5}$ & $X_{6}$ & $X_{7}$ \\
\hline$X_{1}$ & Low demand for science in the economy & 0 & 0 & 0 & 0.369 & 0.140 & 0 & 0 \\
\hline$X_{2}$ & Inefficient system of state management of science & 0.535 & 0 & 1 & 0.576 & 0.365 & 0.833 & 0.613 \\
\hline$X_{3}$ & Low level of communication (integration processes) & 0.103 & 0 & 0 & 0.055 & 0.025 & 0 & 0.051 \\
\hline$X_{4}$ & Lack of funding and other socio-economic incentives & 0 & 0 & 0 & 0 & 0.289 & 0.167 & 0 \\
\hline$X_{5}$ & Low level of effectiveness of scientific results, low export potential & 0 & 0 & 0 & 0 & 0 & 0 & 0 \\
\hline$X_{6}$ & Staffing problem & 0.321 & 0 & 0 & 0 & 0.181 & 0 & 0.336 \\
\hline$X_{7}$ & Low level of authority of science in the society & 0.041 & 0 & 0 & 0 & 0 & 0 & 0 \\
\hline
\end{tabular}

However, some of the problems of development of science under conditions a country's adapting to the digitalization of the economy cannot be quantified. To solve fuzzy problems, the evaluation is carried out in linguistic terms (linguistic variables) on the basis of expert assessment. The paper proposes a scale for evaluating problems that are described by linguistic variables and have the fuzzy tendency of values of growth rates, based on the Fibonacci series. The linguistic scale is as follows: "Significant increase" - growth rate 1.612; "Considerable increase" - 1.309; "Insignificant increase" - 1.119; "Unchanged" - 1; "Insignificant decrease" science under conditions of adapting to the digitalization of the economy is to calculate matrix $A$ (formula 2) characterizing the degree of causal effect of one problem on the other ones being analyzed. For quantitative indicators, the calculation is carried out with the help of the Pearson correlation coefficient based on the data of the State Statistics Service of Ukraine for the period 2000-2018 [12].

Table- III: Matrix A, presenting the values of coefficients of cause-effect relations between the factor $j$ and the factor $i$

\begin{tabular}{|c|l|c|c|c|c|c|c|c|}
\hline Denotation & \multicolumn{1}{|c}{ Group of problems } & $X_{1}$ & $X_{2}$ & $X_{3}$ & $X_{4}$ & $X_{5}$ & $X_{6}$ & $X_{7}$ \\
\hline$X_{1}$ & Low demand for science in the economy & 1 & 0.942 & 0.618 & -0.395 & 0.942 & -0.114 & -0.311 \\
\hline$X_{2}$ & Inefficient system of state management of science & 0.942 & 1 & 0.618 & 0.942 & 0.618 & 0.309 & 0.618 \\
\hline$X_{3}$ & Low level of communication (integration processes) & 0.618 & 0.618 & 1 & 0.618 & 0.309 & 0.618 & 0.309 \\
\hline$X_{4}$ & Lack of funding and other socio-economic incentives & 0.618 & 0.942 & 0.618 & 1 & 0.942 & -0.105 & -0.177 \\
\hline$X_{5}$ & $\begin{array}{l}\text { Low level of effectiveness of scientific results, low export } \\
\text { potential }\end{array}$ & 0.942 & 0.618 & 0.309 & 0.942 & 1 & 0.618 & 0.791 \\
\hline$X_{6}$ & Staffing problem & -0.114 & 0.309 & 0.618 & -0.105 & 0.791 & 1 & 0.309 \\
\hline$X_{7}$ & Low level of authority of science in the society & -0.311 & 0.618 & 0.309 & -0.177 & 0.309 & 0.309 & 1 \\
\hline
\end{tabular}

Based on the results obtained and the calculation of the matrix $A \times L$, a cognitive model for studying problems of development of science under conditions of Ukraine's
- 0.942; "Considerable decrease" - 0.618; "Significant decrease" - 0.309; "Very significant decrease" - 0.119.

According to the proposed linguistic evaluation scale: a low level of communication (integration processes) -0.942 , an inefficient system of state management of science (insignificant increase - 1.119), a low level of authority of science in the life of the society -0.618 .

Thus, the values of coefficients of cause-effect relations among the problems of development of science under conditions of adapting to the digitalization of the economy were obtained. The results are summarized in Table 3 . adaptation to the digitalization of the economy was built (Fig. $3)$. 


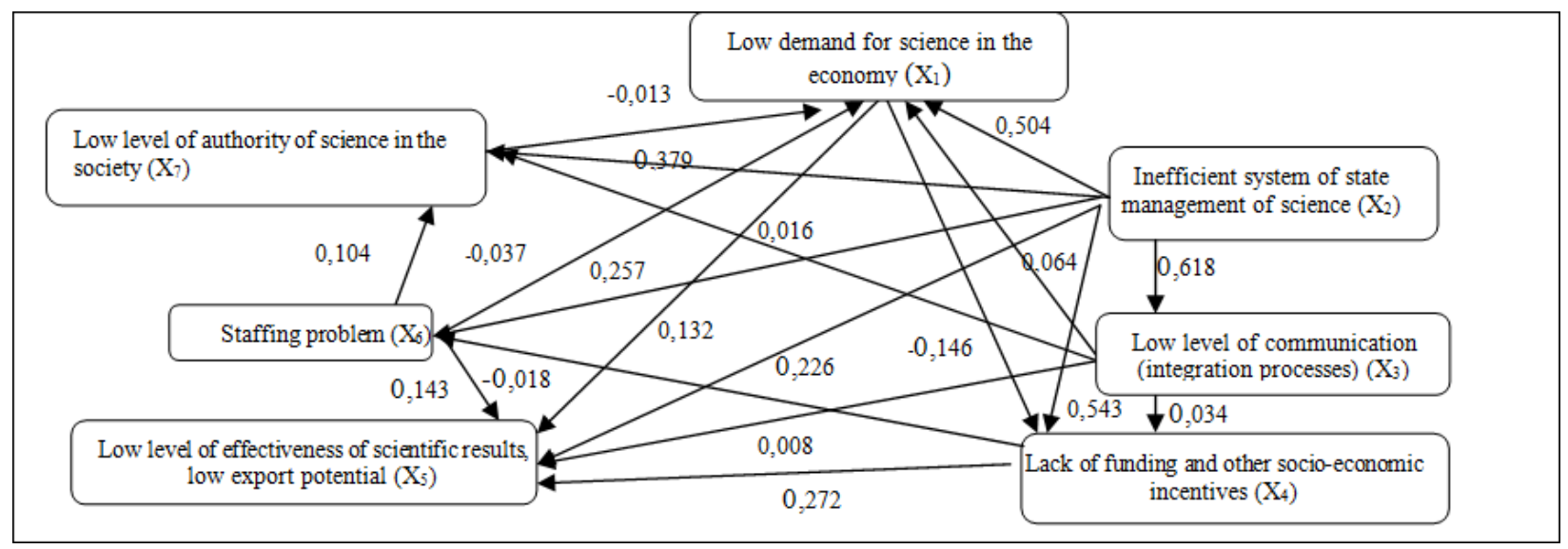

Fig. 3. Cognitive model for studying problems of development of science in Ukraine under conditions of adapting to the digitalization of the economy

The proposed model for studying problems of development of science in Ukraine under conditions of adapting to the digitalization of the economy makes it possible to reveal risks and determine possibilities for reforming the scientific sphere. So, the lack of clear priorities in the field of development and implementation of digital technologies at the state level can result in an increase in the gap between the level of innovative and economic development of advanced countries and Ukraine as well as a significant decrease in its competitiveness and threats to its economic security. The low level of authority of Ukraine's science in the society leads to impossibility of increasing demand for its scientific developments in the digital sphere as well as of forming appropriate human resources to ensure the implementation of digital technologies. The decrease in the share of innovatively active enterprises and the unwillingness of Ukrainian businesses to introduce digital innovative developments exacerbates the country's economic problems, results in a drop in its global competitiveness. The lack of adequate funding for the scientific sphere and the outdated material and technical base of research organizations makes it impossible to develop competitive scientific products in the field of digital technologies. The low level of communication and integration between Ukrainian research organizations and the international scientific community does not allow taking part in the development of modern digital technologies corresponding to international standards. All this leads to unsatisfactory results in the field of digital technologies, exacerbation of the current problems and a slowdown in the processes of Ukraine's adapting to conditions of the digital economy. The problems can only be solved through reforming the scientific sphere, which should be started with setting the priorities for the development of the Ukrainian science that are consistent with global trends and elaborating an appropriate strategy for the development of science in the country.

\section{CONCLUSION}

Modern global digitalization processes affect all spheres of economic activity, increasing the gap between countries in transition and developed ones. Decreasing the digital inequality among nations is possible only due to both ensuring the possibility of introducing digital technologies and developing their own scientific products in order to adapt to conditions of the digital economy. Therefore, studying problems of development of science in the digital economy is of importance not only for Ukraine but also for other countries of the world that are interested in enhancing their competitiveness.

The application of the methodological approach that is based on the building of a cognitive model for studying problems of development of science under conditions of adapting to the digitalization of the economy makes it possible to assess the current situation in the Ukrainian science and analyze the interaction of the main problems of development of science, with regard to the existing trends and available resources. The conducted research allows to conclude that there is a need for reforming the scientific sphere in Ukraine. Taking into account the current trends, it is the only way to ensure the functioning of socio-economic systems under conditions of the digitalization of the economy without a decline in the level of the country's competitiveness and economic security.

\section{REFERENCES}

1. UNCTAD. Digital Economy Report. Value creation and capture: implications for developing countries. 2019. Available:

https://unctad.org/en/PublicationsLibrary/der2019_en.pdf

2. European Commission. Expert Group on Taxation of the Digital Economy, 2014.

3. World Bank. World Development Report 2019: The Changing Nature of Work. World Development Report. Washington, DC: World Bank. 2019. Available: https://openknowledge.worldbank.org/handle/10986/304 35

4. R. Heeks, "Information and Communication Technology for Development" (ICT4D), Routledge, Abingdon, UK, 2018

5. OECD. Data in the digital age. Paris. (2019). Available: https://www.oecd.org/going-digital/data-in-the-digital-ag e.pdf

6. R. Bukht, and R. Heeks. "Defining, Conceptualising and Measuring the Digital Economy". Centre for Development Informatics, University of Manchester, UK 2017 Available: 
https://diodeweb.files.wordpress.com/2017/08/diwkppr6 8-diode.pdf

7. T. Elmasry, et al., Digital Middle East: Transforming the Region into a Leading Digital Economy, McKinsey \& Company, New York, NY. 2016. Available: http://www.mckinsey.com/global-themes/middle-eastand -africa/digital-middle-east-transforming-the-region-into-a -leading-digital-economy

8. Z. Avdeeva, and S. Kovriga, "The technology of the strategic goal-setting and monitoring of a system development on the basis of cognitive mapping”. Procedia Computer Science, 2017

9. L. Ginis, G. Gorelova, and A. Kolodenkova, "Cognitive and simulation modeling of development of regional economy system". International Journal of Economics and Financial Issues. 2016, Vol 6, No 5S, - p. 97- 103.

10. M. Kyzym, O. Reshetniak, and O. Lelyuk "Simulating Development of Science in a Country with the Use of the Cognitive Approach". SHS Web Conf., 67, 2019. 01008. Available https://doi.org/10.1051/shsconf/20196701008

11. T. Saaty, and M. Sodenkamp, "Making decisions in hierarchic and network systems", Int. J. Applied Decision Sciences, 1, 24-79, 2008

12. The State Statistics Service of Ukraine [online]. 2019. Available: www.ukrstat.gov.ua/

\section{AUTHORS PROFILE}

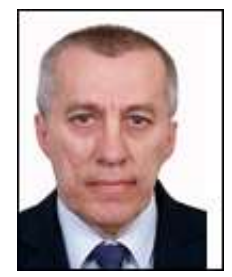

Mykola Kyzym - Doctor of Sciences (Economics), Professor, Corresponding Member of the National Academy of Sciences of Ukraine, Honored Economist of Ukraine. From 2006 to the present, he has been working in the Research Centre for Industrial Problems of Development of the Nattional Academy of Sciences of Ukraine (Ukraine, Kharkiv) as Director. Also working in the Kharkiv National University of Economics named after Simon Kuznets (Ukraine, Kharkiv) as Professor of the Department of Public Administration and Regional Economics. He is the author of more than 500 scientific works, including more than 90 monographs. His research interests include: association of Ukraine with the EU, areas for development and cooperation; model of society, society crisis and reforms; crisis events in the economy and their early recognition; energy security and energy efficiency of the economy; industrial policy and priorities for modernizing the economy; competitiveness of the national economy and ensuring economic security of the state.

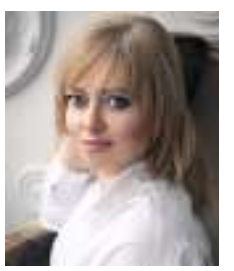

Viktoriia Khaustova - Doctor of Sciences (Economics), Professor. Currently working in the Research Centre for Industrial Problems of Development of the National Academy of Sciences of Ukraine (Ukraine, Kharkiv) as Head of Section for Industrial Policy and Innovative Development. Also working in the Kharkiv National University of Construction and Architecture (Ukraine, Kharkiv) as Professor of Finance and Credit Department. She is the author of more than 300 scientific, educational and methodological works, including more than 50 monographs. Her research interests include: industrial policy and modernization of economic sectors of the country; scientific and technological, and innovation policy of the country; global processes and national problems of development of the industrial sector, scientific and technological development, and scientific and innovation activities; development of recommendations for strategic planning and organization (improvement) of business processes of business entities; cluster policies and technological platforms; integration processes in the economy and their influence on the socio-economic development.

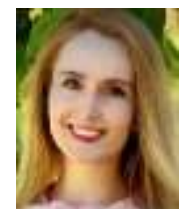

Elena Reshetnyak - PhD in Economics, Associate professor. Currently a doctoral student at the Research Centre for Industrial Problems of Development of the National Academy of Sciences of Ukraine (Ukraine, Kharkiv). Also working as associate professor at the Department of International E-Commerce and Hotel and Restaurant Business at the Faculty of International Economic Relations and Tourism of V. N. Karazin Kharkiv National University (Ukraine, Kharkiv). She is the author of more than 100 scientific, educational and methodological works, including 8 monographs. Her research interests include: research into the problems of scientific development in the modern economy; scientific and technological, and innovation policy of the country; model of society and reforms; scientific and technological development, and scientific and innovation activities; development of recommendations for strategic planning and organization (improvement) of business processes of business entities; cluster policies; integration processes in the economy and their influence on the socio-economic development.

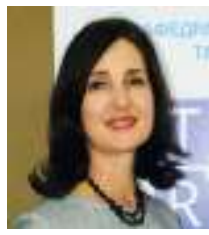

Natalia Danko - PhD in Economics, Associate professor, Head of Department of International E-Commerce and Hotel and Restaurant Business at the Faculty of International Economic Relations and Tourism of V. N. Karazin Kharkiv National University (Ukraine, Kharkiv). She is the author of more than 100 scientific, educational and methodological works, including 5 monographs. Her research interests include scientific and technological, and innovation policy of the country; global processes and national problems of development of the industrial sector, integration processes in the economy and their influence on the socio-economic development; cluster policies; problems of development of touristic and hospitality business in Ukraine. 